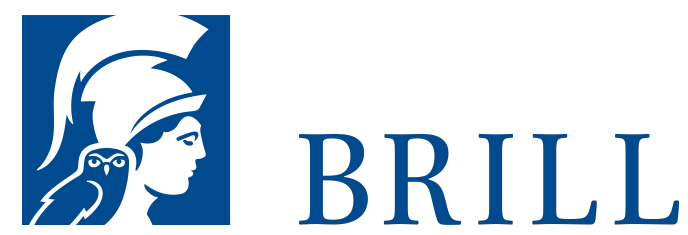

\title{
Die missverstandene Revolution
}

Zum Weltbild der modernen Physik

Author: Franz von Kutschera

Der Ãœbergang von der klassischen zur modernen Physik ist immer als eine Revolution angesehen worden. Die Relativit Ãatstheorie hat dazu gefÃ $1 / 4 h$ hrt, dass sich unsere Vorstellungen von Raum und Zeit grundlegend verÃăndert haben, und die Quantenmechanik hat die MÃ $₫$ glichkeit einer widerspruchsfreien Beschreibung der Wirklichkeit in Frage gestellt. Dieses Buch ist ein Versuch zu zeigen: Diese Konsequenzen sind keineswegs zwingend. Die eigentliche Revolution liegt vielmehr in der Einsicht, dass die moderne Physik sich nicht mit der erkenntnistheoretischen NaivitÃat der klassischen Physik vertrÃagt. Die physische Welt lãăsst sich nicht so erkennen, wie sie an sich beschaffen ist, unabhÃơngig von unseren menschlichen Wahrnehmungen, sondern nur so, wie sie sich in unseren Erfahrungen zeigt

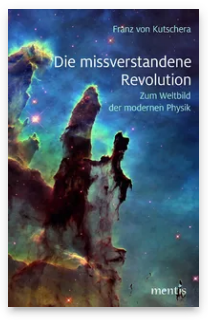

Pages: 92 Seiten

Language:

German

Subjects:

General,

Philosophy

Publisher: Brill | mentis

E-Book (PDF)

Released online:

o1 Sep 2017

ISBN: 978-3-

95743-833-1

List price

Paperback

Publication date:

o1 Sep 2017

ISBN: 978-3-

95743-107-3

List price 
For more information see brill.com

Order information: Order online at brill.com +44330 333 0049 | customerservices@brill.com Submission information: brill.com/authors

Titles published by Brill | Fink, Brill | mentis or Brill | Schöningh: +49(o)715413279216| brill@brocom.de 